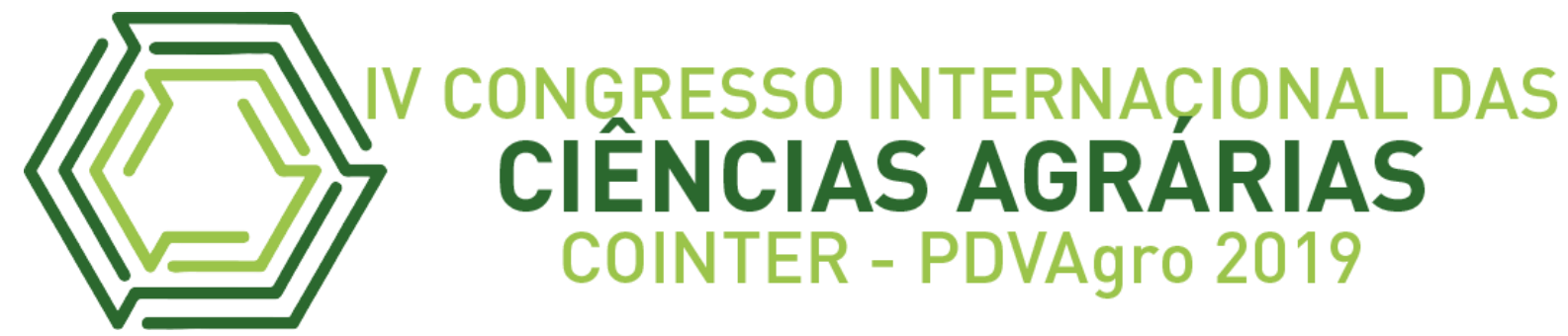

\title{
DESENVOLVIMNETO DE CLASSIFICADOR A PARTIR DE REDES NEURAIS ARTIFICIAIS PARA A CASCA DA MANGA IN NATURA
}

\section{DESARROLLO DE CLASIFICADOR DE REDES NEURALES ARTIFICIALES PARA LA PEELING DEL MANGO FRESCO}

\section{DEVELOPER OF CLASSIFIER FROM ARTIFICIAL NEURAL NETWORKS FOR IN NATURA MANGO SLEEVE}

\author{
Apresentação: Comunicação Oral \\ Cinara Vanessa de Muniz Almeida ${ }^{1}$; Suzana Pedroza da Silva ${ }^{2}$; Marteson Cristiano dos \\ Santos Camelo ${ }^{3}$
}

DOI: $\underline{\text { https://doi.org/10.31692/2526-7701.IVCOINTERPDVAgro.2019.0085 }}$

\begin{abstract}
Resumo
As indústrias processadoras de frutas geram grandes quantidades de resíduos com potencial aplicação em alimentos mediante processos de conservação, adição de substâncias e processos de secagem, tendo em vista a manutenção da qualidade destes resíduos. $\mathrm{O}$ desenvolvimento de classificadores através de redes neurais artificiais (RNA) se mostra muito eficiente para a classificação e reconhecimento de qualidade em frutas o que viabiliza a classificação de resíduos durante a etapa de conservação. O presente trabalho tem como objetivo desenvolver um classificador a partir de redes neurais artificiais para a casca da manga in natura avaliada em decorrência da conservação das mesmas pelo emprego de refrigeração e inibidores de reações com a finalidade de produzir farinhas da casca de manga. As mangas foram adquiridas no comércio local de Garanhuns-PE. Foram lavadas, sanitizadas, descascadas, removida a polpa, homogeneizadas e separadas em seis grupos: controle (sem tratamento) e cinco com tratamentos (A $\left(1,0 \%(\mathrm{AA})+1,0 \%\left(\mathrm{CaCl}_{2}\right)\right)$; B $\left(2,0 \%(\mathrm{AA})+2,0 \%\left(\mathrm{CaCl}_{2}\right)\right)$; C $\left(2,0 \%(\mathrm{AA})+1,0 \%\left(\mathrm{CaCl}_{2}\right) \mathrm{D}\left(1,5 \%(\mathrm{AA})+1,5 \%\left(\mathrm{CaCl}_{2}\right)\right) ; \mathrm{E}\left(1,0 \%(\mathrm{AA})+2,0 \%\left(\mathrm{CaCl}_{2}\right)\right)\right.$. As cascas foram acondicionadas em embalagens de polietileno e armazenadas sob refrigeração $\left(2{ }^{\circ} \mathrm{C}, 5^{\circ} \mathrm{C}\right.$ e $\left.7{ }^{\circ} \mathrm{C}\right)$. Para o desenvolvimento do classificador via redes neurais foi utilizado o MATLAB ${ }^{\circledR}$, o classificador distingue cada amostra como aptas para consumo ou inapta para consumo. Através da análise de componentes principais foram selecionadas as variáveis que mais afetam as características da casca da manga para consumo. Foram utilizadas 98 amostras para etapa de treinamento, validação e teste, e 97 amostras para etapa de simulação do classificador. O desenvolvimento classificado para casca da manga a partir de redes neurais se mostrou eficiente apresentando um erro de 8,2\% para etapa de simulação e com capacidade de classificar adequadamente 89 amostras das 97 amostras empregadas na etapa de simulação.
\end{abstract}

\footnotetext{
${ }^{1}$ Graduanda em Engenharia de Alimentos, UFRPE, Garanhuns, cinaravanessa76@gmail.com

${ }^{2}$ Doutora em Engenharia Química, UFRPE, Garanhuns, suzpedroza@gmail.com

${ }^{3}$ Doutor em Engenharia Química, UFRPE, Garanhuns, martesonpe@gmail.com
} 
Palavras-Chave: Casca de Manga, Classificação, Reaproveitamento, Redes Neuronais.

\title{
Resumen
}

Las industrias de procesamiento de fruta generan grandes cantidades de residuos con aplicación potencial en alimentos a través de procesos de conservación, adición de sustancias y procesos de secado, con el fin de mantener la calidad de estos residuos. El desarrollo de clasificadores a través de redes neuronales artificiales (ARN) es muy eficiente para la clasificación y el reconocimiento de la calidad en frutas, lo que permite la clasificación de residuos durante la etapa de conservación. El presente trabajo tiene como objetivo desarrollar un clasificador de redes neuronales artificiales para la cáscara de mango fresco evaluada como resultado de su conservación mediante el uso de inhibidores de la refrigeración y reacción para producir harinas de cáscara de mango. Los mangos fueron comprados en el comercio local de Garanhuns-PE. Se lavaron, se desinfectaron, se pelaron, se retiró la pulpa, se homogeneizaron y se separaron en seis grupos: control (sin tratamiento) y cinco con tratamientos (A (1.0\% (AA) + 1.0\% $\left.\left(\mathrm{CaCl}_{2}\right)\right)$; B $\left(21.0 \%(\mathrm{AA})+2.0 \%\left(\mathrm{CaCl}_{2}\right)\right) \mathrm{C}(2.0 \%(\mathrm{AA})$ $+1.0 \%\left(\mathrm{CaCl}_{2}\right) \mathrm{D}\left(1.5 \%(\mathrm{AA})+1.5 \%\left(\mathrm{CaCl}_{2}\right) \mathrm{E}\left(1,0 \%(\mathrm{AA})+2,0 \%\left(\mathrm{CaCl}_{2}\right)\right)\right.$ Las envolturas se empaquetaron en recipientes de polietileno y se almacenaron refrigeradas $\left(2{ }^{\circ} \mathrm{C}, 5{ }^{\circ} \mathrm{C} \mathrm{y}\right.$ $7{ }^{\circ} \mathrm{C}$ ). El clasificador MATLAB ${ }^{\circledR}$ se usó para clasificar las redes neuronales, durante las cuales se seleccionaron los criterios de clasificación para cada análisis más significativo del análisis de componentes principales, se usaron 98 muestras para entrenamiento, validación y pruebas, y 97 muestras para Etapa de simulación del clasificador El desarrollo clasificado para la cáscara de mango de redes neuronales demostró ser eficiente, presentando un error del $8.2 \%$ para la etapa de simulación y con la capacidad de clasificar correctamente 89 Muestras de las 97 muestras empleadas en el paso de simulación.

Palabras Clave: Clasificación, Peeling de Mango, Redes neuronales, Reutilización.

\begin{abstract}
The fruit processing industries generate large quantities of residues with potential application in food through preservation processes, addition of substances and drying processes, in order to maintain the quality of these residues. The development of classifiers through artificial neural networks (RNA) is very efficient for classification and quality recognition in fruits, which enables the classification of residues during the conservation stage. The present work aims to develop a classifier from artificial neural networks for fresh mango peel evaluated as a result of their conservation by the use of refrigeration and reaction inhibitors in order to produce mango peel flours. The mangoes were purchased from the local Garanhuns-PE trade. They were washed, sanitized, peeled, pulp removed, homogenized and separated into six groups: control (no treatment) and five with treatments $(\mathrm{A}(1.0 \%(\mathrm{AA})+1.0 \%(\mathrm{CaCl}))$; $\mathrm{B}(2$ $\left.1.0 \%(\mathrm{AA})+2.0 \%\left(\mathrm{CaCl}_{2}\right)\right) \mathrm{C}\left(2.0 \%(\mathrm{AA})+1.0 \%\left(\mathrm{CaCl}_{2}\right) \mathrm{D}\left(1.5 \%(\mathrm{AA})+1.5 \%\left(\mathrm{CaCl}_{2}\right) \mathrm{E}\right.\right.$ $\left(1.0 \%(\mathrm{AA})+2.0 \%\left(\mathrm{CaCl}_{2}\right)\right)$ The shells were packed in polyethylene containers and stored refrigerated $\left(2{ }^{\circ} \mathrm{C}, 5{ }^{\circ} \mathrm{C}\right.$ and $\left.7{ }^{\circ} \mathrm{C}\right)$. The MATLAB ${ }^{\circledR}$ classifier was used to classify the neural networks, during which the classification criteria were selected for each most significant analysis from principal component analysis, 98 samples were used for training, validation and testing, and 97 samples for classifier simulation stage The development classified for mango peel from neural networks proved to be efficient presenting an $8.2 \%$ error for the simulation stage and with the ability to properly classify 89 samples of the 97 samples employed in the simulation step.
\end{abstract}


Keywords: Classification, Mango Peel, Neural Networks, Reuse.

\section{Introdução}

O processamento de frutas por vezes resulta na eliminação de partes consideradas não comestíveis da fruta como cascas e sementes, porem muitas destas apresentam potencial de ser aplicada em dietas e significativas propriedades nutracênicas a alimentação, além de reduzir os impactos ambientais decorrentes dos resíduos orgânicos provenientes das indústrias de processamento de frutas.

A casca de manga, por exemplo, poderia ser incorporada em dietas na forma de farinha, visto que o consumo de farinhas é altamente significativo na dieta dos brasileiros e a casca da manga apresenta características e propriedades interessantes para o consumo. Por vezes o processamento destas cascas de manga não pode ocorrer de maneira imediata sendo assim necessária a utilização de métodos de conservação até que ocorra o processamento, uma vez que as cascas de frutas sofrem com problemas de escurecimento oxidativo, perda de massa, desenvolvimento de microrganismos e atuação de enzimas.

Diversos métodos de conservação podem ser empregados com a finalidade de inibir reações indesejáveis assim como manter as características adequadas para o consumo da mesma, porem a depender da finalidade a que estas se destinam alguns métodos se tornam mais adequados, como o emprego de refrigeração e a aplicação de soluções visando reduzir reações desfavoráveis a conservação da casca, visto que se trata de um tecido vegetal. A utilização de substâncias como cloreto de cálcio e ácido ascórbico apresentam funções importantes no que se trata de conservação de características de tecidos vegetais, inibindo reações oxidativas e prevenindo o escurecimento enzimático.

Para verificação do estádio de conservação da casca da manga é necessário o acompanhamento de parâmetros físico-químicos importantes, para que através da quantificação destes possa ser determinada a aptidão da casca para ser processada na forma de farinha.

O classificador atua através das entradas, que são os resultados das análises físicoquímicas realizadas durante o período de conservação da casca da manga, a utilização dos critérios de classificação, para enfim como saída obter a casca da manga classificada em apta para o consumo ou não apta para o consumo. 
Visando reconhecimento das cascas de manga com aptidão para serem aplicadas ao processamento na forma de farinha, a utilização de softwares de classificação tem se tornado uma ótima opção no intuito de obter resultados rápidos, precisos e confiáveis. No sentido as redes neurais artificiais vêm ganhando espaço.

Deste modo, busca-se com esse trabalho, desenvolver um classificador a partir de redes neurais artificiais para a casca da manga in natura avaliada em decorrência da conservação das mesmas pelo emprego de refrigeração e inibidores de reações com a finalidade de produzir farinhas da casca de manga.

\section{Fundamentação Teórica}

O aproveitamento integral de alimentos é típico de países em desenvolvimento (LEMOS et al., 2015). Na indústria de processamento de alimentos após o uso da polpa das frutas grande parte das vezes ocorre o descarte dos resíduos como cascas e sementes, estas por sua vez podem apresentar nutrientes que poderiam ser utilizados na fortificação alimentar ou na composição de alimentos (MORENO, 2016).

A casca e a semente da manga apresentam cerca de 40 a $50 \%$ da massa total do fruto, ou seja, o que para as indústrias seria descartada na forma de rejeitos, poderiam ter outras finalidades acarretando em benefícios a nutrição do consumidor pela incorporação de fibras e compostos com atividade antioxidante, redução de custos para indústria, redução dos impactos ambientais (RYBKA, LIMA e NASSUR, 2018).

Dentre as variedades de mangas, a Tommy Atkins é a mais exportada pelo Brasil e uma das mais cultivadas, isto se deve a sua boa produtividade, boa capacidade de adaptação a diferentes ambientes de cultivo e por apresentar boa tolerância a doenças. (MENDES, 2013).

Do ponto de vista nutricional, a casca da manga apresenta características nutricionais importantes, (PADILHA; BASSO, 2015). Devido a sua perecibilidade as cascas da manga devem passar por processos de conservação a fim de aumentar sua vida útil, seja pela adição de conservantes e inibidores de reações, processos que usam resfriamentos ou congelamentos; utilização de embalagens e atmosferas modificadas; aplicação de biofilmes; métodos de secagem ou ainda a combinação de mais de um destes.

Segundo Lemos et al. (2013) os resíduos provenientes da agroindústria de frutas podem ser melhor aproveitados quando são submetidos a processos de secagem. Um produto obtido por meio deste processo são as farinhas, de acordo com resolução de diretoria 
colegiada - RDC No 263, de 22 de setembro de 2005 da ANVISA farinhas são "os produtos obtidos de partes comestíveis de uma ou mais espécies de cereais, leguminosas, frutos, sementes, tubérculos e rizomas por moagem e/ou outros processos tecnológicos considerados seguros para produção de alimentos."

Por vezes o processamento destas cascas de manga não pode ocorrer de maneira imediata sendo assim necessária a utilização de métodos de conservação até que ocorra o processamento, segundo Miguel (2008) até o processamento, as cascas de frutas sofrem com problemas de escurecimento oxidativo, perda de massa, desenvolvimento de microrganismos e atuação de enzimas.

A utilização de substâncias como cloreto de cálcio e ácido ascórbico apresentam funções importantes no que se trata de conservação de características de frutas, pois o cálcio presente no cloreto de cálcio interage com a pectina presente na parede celular do alimento formando o pectato de cálcio proporcionando firmeza e melhora na textura dos mesmos e; o ácido ascórbico pelo seu poder antioxidante, muito usado em frutas, vegetais e hortaliças inibindo reações oxidativas e prevenindo o escurecimento enzimático (MIGUEL, 2008).

Para auxiliar no processamento de dados químicos, na análise de alimentos, técnicas analíticas exploratórias são frequentemente aplicadas, com isto as redes neurais surgiram como uma área da informática que têm seus princípios fundamentais assentados nos trabalhos de modelagem biológica do cérebro humano, ligados as frações cognitivas e comportamentais, comumente identificadas como uma subespecialidade da Inteligência Artificial, outras vezes, como uma classe de modelos matemáticos para problemas de classificação e reconhecimento de padrões (RAMOS, 2013). A classificação identifica os objetos agrupando-os em um dos conjuntos de classes finitos que envolvem a comparação de características medidas (DEBSKA e GUZOWSKA-SWIDER, 2011; SAUTHIERA et al., 2019).

A redes neurais artificiais (RNA) são basicamente programas de computador que tem sua origem fundamentada em neurônios biológicos, com isso ela é capaz de simular o processo do cérebro humano. $\mathrm{O}$ desenvolvimento de redes neurais baseadas em deep learning é muito eficiente para a classificação e reconhecimento de frutas (BHARGAVA e BANSAL, 2018).

Com relação às RNA's, é viável o desenvolvimento de modelos que permitam estabelecer relações entre a entrada de padrões de classificação, análise dessa informação e a 
saída da classificação definida. A rede neural deve aprender a reconhecer padrões de entrada e definir a saída segundo as classes. Diante disto, a RNA apresenta um número de nós (neurônios) da camada de entrada a qual corresponde ao número de entradas da RNA.

Os neurônios da camada oculta e de saída são conectados a todos os nós na camada de processo por um peso numérico associado. $\mathrm{O}$ peso conectando dois neurônios serve para regular a magnitude do sinal que passa entre eles (DEBSKA e GUZOWSKA-SWIDER, 2011)

Cada neurônio também possui um valor de limite único chamado bias, o mapeamento de entrada-saída de cada nó na rede é obtido com uma função de ativação, e obtém-se uma saída, se a saída obtida quando comparada com a saída desejada não estiver igual, o erro é então calculado e é propagado a partir da camada de saída até a camada de entrada, e os pesos das conexões das unidades das camadas vão sendo modificados conforme o erro é retro propagado (DEBSKA e GUZOWSKA-SWIDER, 2011; RAMOS, 2013)

As RNA podem ser aplicadas a vários tipos de controle de qualidade de produtos alimentícios, e a classificação contribui com esta estrutura, na qual a simulação artificial do pensamento humano é feita para formar juízos sofisticados de forma instantânea, correta e persistente (DEBSKA e GUZOWSKA-SWIDER, 2011; BHARGAVA e BANSAL, 2018).

\section{Metodologia}

\section{OBTENÇÃO DOS DADOS DE ENTRADA DA REDE NEURAL}

As mangas foram adquiridas no comércio local de Garanhuns-PE, foram lavadas, sanitizadas e aplicados 5 tratamentos com variações nas concentrações de ácido ascórbico e cloreto de cálcio de acordo com a Tabela 1 e então foram armazenadas em recipientes de polietileno, transparentes, com tampa sob refrigeração $\left(2{ }^{\circ} \mathrm{C}, 5^{\circ} \mathrm{C}\right.$ e $\left.7{ }^{\circ} \mathrm{C}\right)$, para posterior realização das análises físico-químicas a cada 48 h durante 8 dias cada tratamento Todos os tratamentos foram testados nas três temperaturas para melhor determinação da condição ótima de conservação das cascas de mangas

Realizaram-se as análises físico-químicas de: teor de umidade (\%), perda de massa fresca (\%), sólidos solúveis totais $\left({ }^{\circ} \mathrm{Brix}\right), \mathrm{pH}$, acidez total titulável (g de ácido cítrico/100 mL de amostra), atividade de água, açúcares $(\mathrm{g} / \mathrm{mL})$, teor de lipídios $(\%)$, teor de fibras $(\%)$ e teor de proteínas (\%); cor e índice de escurecimento. Todas as análises foram realizadas em 
duplicata a cada 48 horas, de acordo com as metodologias descritas por Detmann et al. (2012), Olivas, Mattinson e Barbosa-cánovas (2007), Maldonade, Carvalho e Ferreira (2013) e Instituto Adolfo Lutz (2008), nos Laboratórios de Análise de Alimentos (LAAL), Laboratório de Nutrição Animal (LANA) e na Central de Laboratórios de Apoio à Pesquisa da Unidade Acadêmica de Garanhuns (CENLAG), ambos na Unidade Acadêmica de Garanhuns da Universidade Federal Rural de Pernambuco (UFRPE/UAG).

Tabela 1 - Tipos de tratamentos realizados no processamento mínimo das cascas de manga

\begin{tabular}{l|l}
\hline Identificação do tratamento & Tratamento \\
\hline Controle & sem $\mathrm{AA} \mathrm{e} \mathrm{CaCl}_{2}$ \\
A & $1,0 \%(\mathrm{AA})+1,0 \%\left(\mathrm{CaCl}_{2}\right)$ \\
B & $2,0 \%(\mathrm{AA})+2,0 \%\left(\mathrm{CaCl}_{2}\right)$ \\
C & $2,0 \%(\mathrm{AA})+1,0 \%\left(\mathrm{CaCl}_{2}\right)$ \\
D & $1,5 \%(\mathrm{AA})+1,5 \%\left(\mathrm{CaCl}_{2}\right)$ \\
E* & $1,0 \%(\mathrm{AA})+2,0 \%\left(\mathrm{CaCl}_{2}\right)$ \\
\hline *O tratamento E foi utilizado apenas para maior robustez para rede neural. \\
Fonte: Própria (2019).
\end{tabular}

\section{ANÁLISE DOS COMPONENTES PRINCIPAIS (ACP)}

Os resultados das análises físico-químicas foram submetidos à análise de componentes principais a partir da matriz de correlação de Pearson, utilizando-se o software XLSTAT 2014, com a finalidade de selecionar as análises mais significativas para o processo de conservação da casca da manga e utilizar está como entradas da rede neural artificial.

\section{DESENVOLVIMENTO DE CLASSIFICADOR PARA CASCA DA MANGA ATRAVÉS DE REDES NEURAIS ARTIFICIAIS (RNA)}

Para classificação da casca da manga com base nas características físico-químicas dessas durante o período de 8 dias de armazenamento, foi construída a RNA, que seguiu as etapas expressas no Figura 1. 
Figura 1. Fluxograma das etapas de construção da Rede Neural Artificial

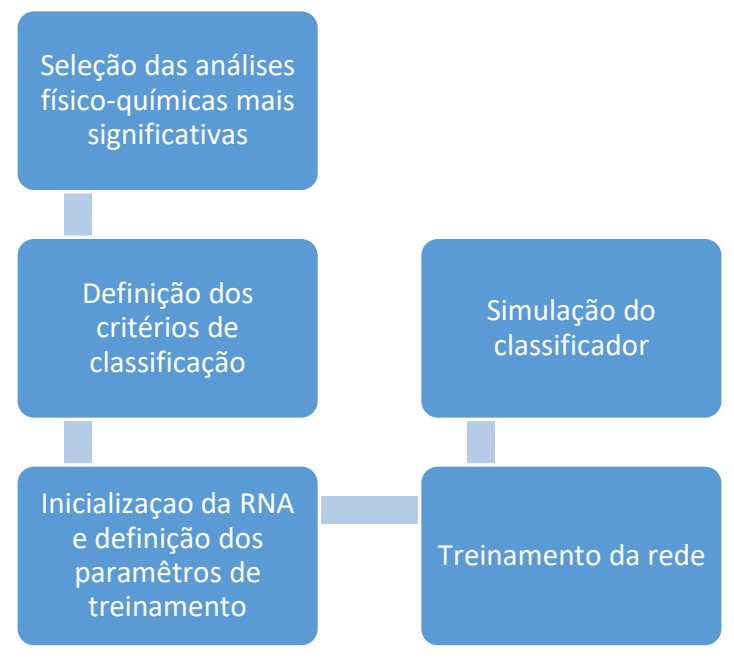

Fonte: Própria (2018).

\section{SELEÇÃO DAS ANÁLISES FÍSICO-QUÍMICAS MAIS SIGNIFICATIVAS}

A ACP foi utilizada para seleção das análises físico-químicas mais significantes, sendo estas: sólidos solúveis totais, acidez total titulável, teor de umidade, teor de proteína e teor de fibra insolúvel em detergente neutro (FDN), apenas os resultados das análises mais significativas foram utilizados como entrada para a rede neural.

\section{DEFINIÇÃO DOS CRITÉRIOS DE CLASSIFICAÇÃO}

O critério de classificação para o desenvolvimento da rede neural indica o valor limitante para classificação, ou seja, o valor máximo do intervalo de valores de uma determinada amostra, no qual a casca é considerada apta para o consumo e processamento, para as amostras que apresentam valores para cada variável inferiores ao critério de classificação determinados, serão consideradas aptas para o consumo, as amostras que não apresentarem valores para cada variável inferiores ao critérios de classificação são consideradas inaptas para o consumo.

Os dados obtidos nas análises físico-químicas da casca da manga foram transferidos do EXCEL para o MATLAB. Esses dados foram analisados e agrupados de acordo com os critérios de classificação para cada análise. 
Os critérios de classificação foram definidos pela literatura, a partir dos máximos valores obtidos para as análises mais significativas. Os critérios de classificação são expressos na Tabela 2.

Tabela 2 - Critérios de classificação Rede Neural Artificial

\begin{tabular}{l|l}
\hline Autor & Análise e resultado \\
\hline Ajila e Rao, 2013 & FDN (\%): 40,60 \\
Imra et al., 2013 & Teor de proteínas (\%): 4,88 \\
Puligundla et al., 2014 & Sólidos solúveis totais ( ${ }^{\circ}$ BRIX): 25,00 \\
Reinoso, 2017 & Acidez total titulável:0,92 g de ácido cítrico/100 mL de amostra \\
Alberton, 2014 & Teor de umidade (\%): 86,80 \\
\hline Fonte: Própria (2019). &
\end{tabular}

Através da literatura, para o teor de fibras na casca da manga foram verificados valores que variavam de 5,47 a 56,55 \%, sendo o maior valor encontrado por Ajila e Rao (2013) em seu estudo acerca das fibras dietéticas da casca da manga.

A respeito do teor de proteínas, os valores variavam de 1,24 a 4,88 \%, sendo o maior valor encontrado por Imra et al. (2013) em seu estudo a respeito dos perfis químicos de cascas de variedades de manga.

Em relação ao teor de sólidos solúveis totais, os valores variaram de 10,5 a $25{ }^{\circ}$ BRIX, sendo o maior valor encontrado por Puligundla et al. (2014) em seu estudo a respeito do potencial biotecnológico da casca da manga na forma de revisão, para acidez total titulável foi encontrado valores que variavam de 0,09 a 0,92 g de ácido cítrico/100 mL de amostra, porém o maior valor foi obtido por Reinoso (2017) em seu estudo sobre utilização de resíduos de mangas Tommy Atkins para elaboração de barras de cereais.

Foram verificados valores que variavam de 59,9 a 86,8 \%, sendo o maior valor obtido por Alberton (2014), em seu estudo sobre caracterização da manga Tommy Atkins in natura e após a liofilização.

Um exemplo da utilização dos critérios pode ser aplicado as amostras da Tabela 3, onde a amostra 1 é classificada como apta para consumo e processamento devido aos valores para cada variável serem inferiores ao critério de classificação determinados, a amostra 2 apresenta valor para teor de proteína superior ao critério de classificação, por isto é considerada inapta para o consumo. 
Tabela 3 - Classificação das amostras 1 e 2

\begin{tabular}{l|l|l|l}
\hline Amostra & Analise & Resultado & Classificação \\
\hline \multirow{2}{*}{ Amostra 1 } & FDN & 33,563 & \\
& Teor de proteínas & 3,768 & Apta \\
& Acididos solúveis totais & 1,600 & \\
& Teor de umidade & 83,807 & \\
& FDN & 19,489 & \\
& Teor de proteínas & 7,344 & Inapta \\
& Sólidos solúveis totais & 6,000 & \\
& Acidez total titulável & 0,077 & \\
& Teor de umidade & 76,605 & \\
\hline
\end{tabular}

Fonte: Própria (2018).

\section{INICIALIZAÇÃO DA RNA E DEFINIÇÃO DOS PARÂMETROS DE TREINAMENTO}

Para construir a rede neural artificial utilizou-se o software MATLAB ${ }^{\circledR}$; este software é uma linguagem de programação técnica e científica baseados em matriz, em que as soluções e problemas são expressos em linguagem matemática (SILVA, 2013). Além disso, o MATLAB $^{\circledR}$ apresenta uma biblioteca com várias funções matemáticas que podem ser aplicadas a diversos problemas encontrados na engenharia.

Em relação às redes neurais artificiais o MATLAB ${ }^{\circledR}$ possui um toolbox com várias funções para desenvolver redes neurais, que podem ser aplicadas desde problemas de inferência a problemas de reconhecimento de padrões, ou seja, classificação.

A função utilizada para criar a rede neural desenvolvida neste trabalho foi a função patternnet, esta função cria uma estrutura neural própria para problemas de reconhecimento de padrões.

Antes do treinamento da rede neural foram definidos os parâmetros expressos na Figura 2 para rede, sendo estes:

- Número de entradas igual a 5;

- Número de camadas internas igual a 1;

- Número de neurônios na camada interna igual a 10; 
Figura 2. Parâmetros para o primeiro treinamento da rede neural

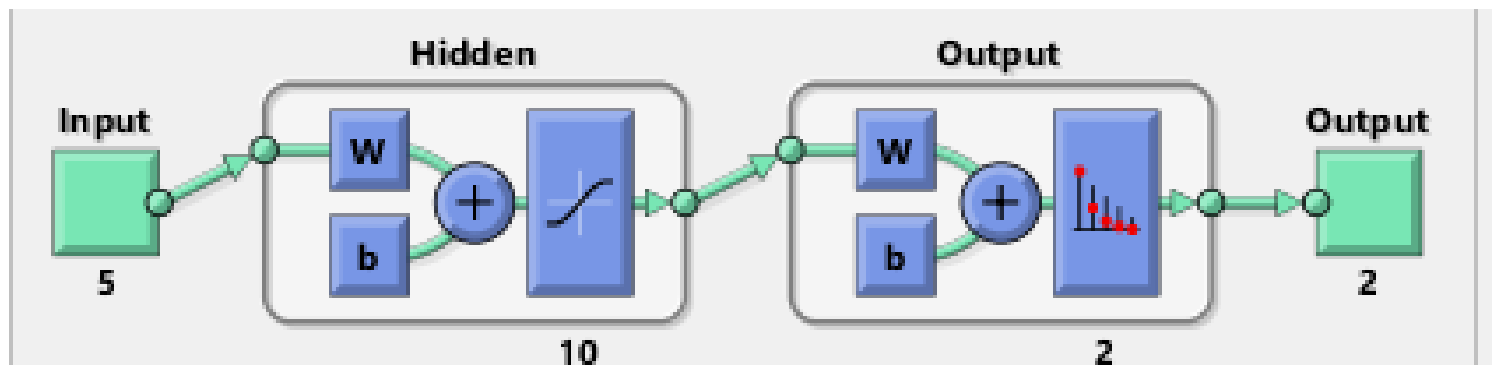

Fonte: Própria (2019).

Foram atribuídos como entrada para rede neural as 5 variáveis avaliadas no estudo de análise de componentes principais, apresentadas na Tabela 3. Desta forma a rede possui 5 neurônios de entrada.

Devido à natureza do problema de classificação o número de saídas da rede foi igual a dois, uma vez que a casca da maga foi classificada como apta ou inapta, para consumo e processamento. Sendo atribuído o valor 1 quando a amostra é apta e 0 quando a amostra não é apta.

\section{TREINAMENTO DA REDE}

O conjunto de dados utilizado para treinamento do classificador, rede neural, possui um total de 98 amostras. O treinamento da RNA inclui três etapas:

- Treinamento: nesta etapa os valores dos pesos e bias da rede são definidos, das 90 amostras utilizadas no treinamento $50 \%$ foram aplicadas nesta etapa.

- Validação: verifica o erro na saída da RNA para os valores de pesos e bias definidos no treinamento, utilizou-se $25 \%$ do total de amostras nesta etapa.

- Teste: etapa similar a validação, verifica o erro na saída da RNA para os valores de pesos e bias definidos no treinamento, utilizou-se $25 \%$ do total de amostras nesta etapa.

\section{SIMULAÇÃO DO CLASSIFICADOR}

A simulação foi realizada por meio da função net, e Para simulação do classificador foram utilizadas 97 amostras, as quais são diferentes das empregadas no processo de treinamento. 


\section{Resultados e Discussão}

A ACP dos tratamentos (FIGURA 3) mostrou que, as análises de maior significância com relação aos tratamentos e o período de conservação foram: sólidos solúveis totais, acidez total titulável, teor de umidade, teor de proteína e teor de fibra insolúvel em detergente neutro (FDN). É possível verificar que o tratamento B apresentou resultados semelhantes ao tratamento D para todas as temperaturas de armazenamento, e maior semelhança para a temperatura de $7{ }^{\circ} \mathrm{C}$ em relação as demais. Ambos apresentaram boas características de conservação com o tempo de armazenamento.

Para a avaliação dos resultados obtidos durante a etapa de treinamento e simulação da rede neural artificial, vale salientar que é verificado na coordenada 1 as amostras consideradas aptas, e para a coordenada 2 as amostras inaptas, na cor verde são representados os acertos da rede, e na cor de rosa são representados os erros da rede.

Ao rodar o modelo classificador desenvolvido via RNA com os dados das análises físico-químicas da casca da manga. Os resultados obtidos durante o treinamento para a rede neural com uma camada interna e número de neurônios igual a 10 são apresentados na Figura 4. É possível verificar $9,2 \%$ de erros, sendo deste verificado que 58 amostras testadas pela rede neural dentre as 98 utilizadas foram consideradas aptas para o consumo e processamento segundo os parâmetros de decisão adotados neste trabalho, foi verificado também que o modelo da RNA identificou 6 amostras como aptas para o consumo quando na verdade estas não se encontram aptas e, 3 amostras consideradas inaptas quando na verdade estavam aptas para o consumo e processamento. 
Figura 3. Análises dos componentes principais (ACP) dos tratamentos em relação à temperatura do primeiro (a) e do último dia (b). (D0T0- tratamento controle dia zero; D0T1- tratamento A dia zero; D0T2- tratamento B dia zero; D0T3- tratamento C dia zero; D0T4- tratamento D dia zero; D4T0- tratamento controle $8^{\circ}$ dia; D4T1tratamento A $8^{\circ}$ dia; D4T2- tratamento B $8^{\circ}$ dia; D4T3- tratamento $\mathrm{C} 8^{\circ}$ dia; D4T4- tratamento $\mathrm{D} 8^{\circ}$ dia).

(a)

Biplot (axes F1 and F2: $\mathbf{5 1 . 9 8 \% ) ~}$

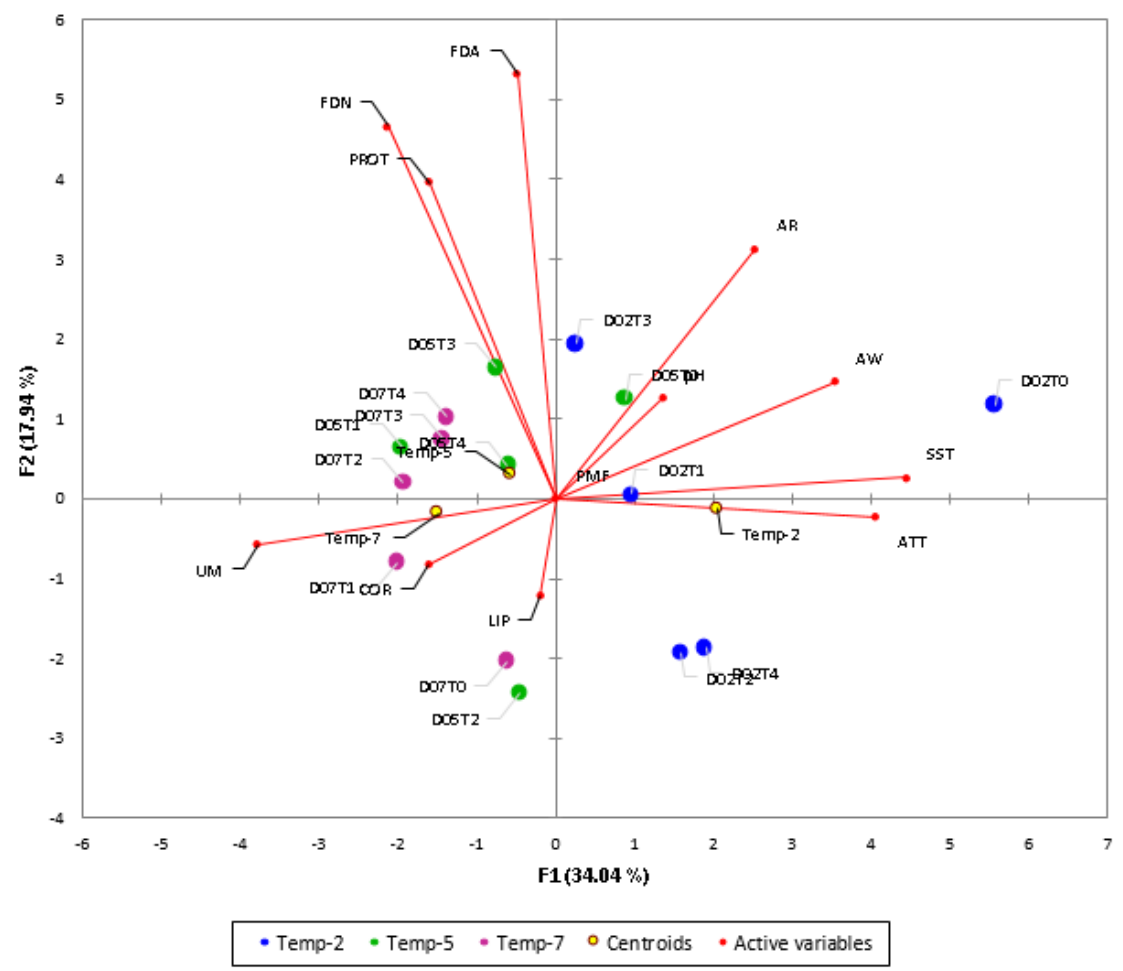

(b)

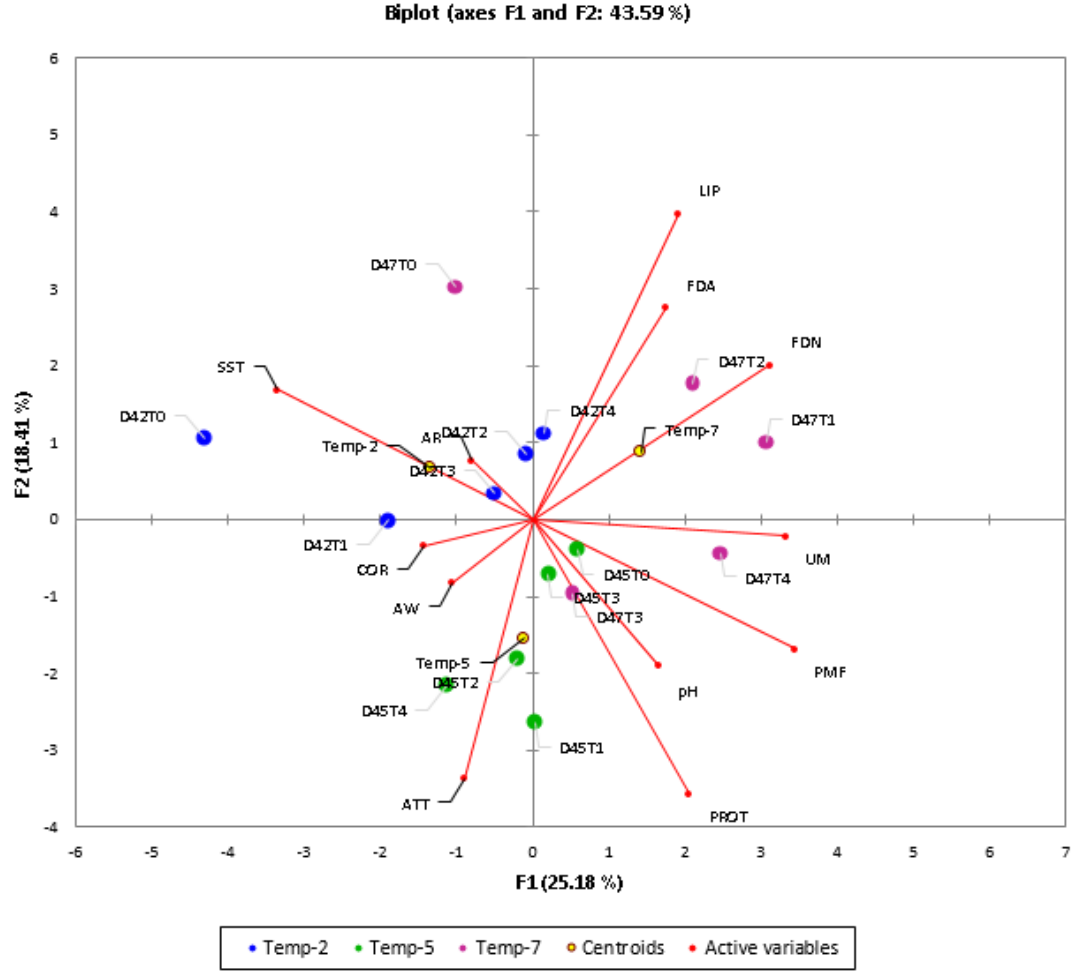

Fonte: Própria (2019). 
Figura 4. Quadro de resultados para treinamento, teste e validação da rede neural artificial com uma camada interna e número de neurônios igual a 10.

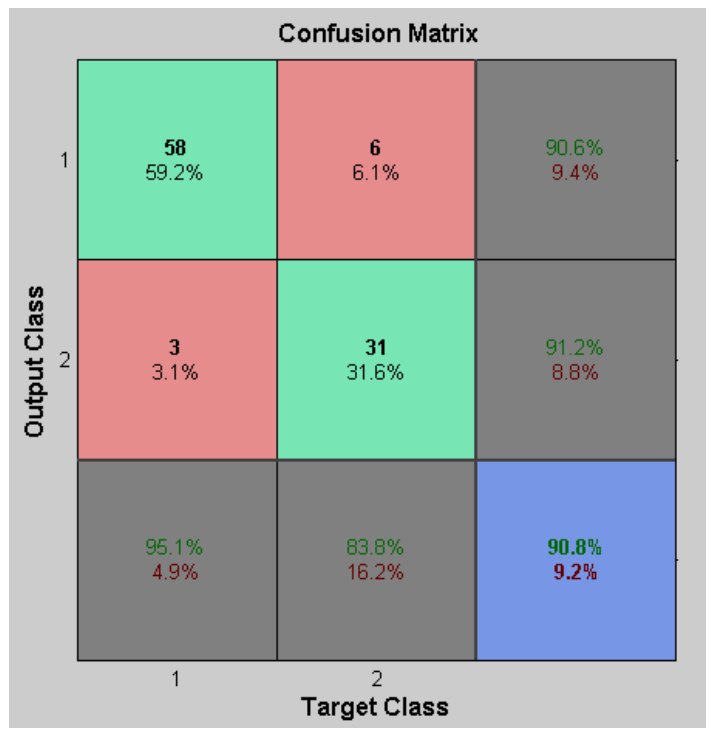

Fonte: Própria (2019).

Para simulação do classificador com uma camada interna e número de neurônios igual a 10 foram obtidos os seguintes resultados expressos na Figura 5 com erro de 8,2\% onde 60 amostras foram consideradas aptas para o consumo de acordo com os parâmetros adotados no estudo; 3 amostras foram consideradas inaptas para o consumo quando na realidade estas eram aptas para o consumo e 5 amostras foram consideradas aptas para o consumo quando na realidade estas se encontravam não aptas para o consumo.

Figura 5. Quadro de resultados para Simulação do classificador com 1 camada interna e número de neurônios 10

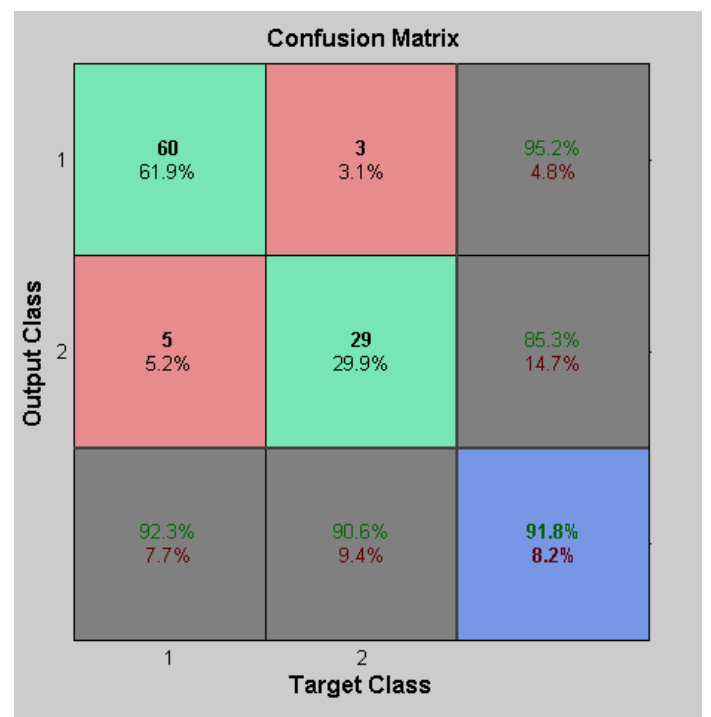

Fonte: Própria (2019). 
Segundo Soares et al. (2014) a arquitetura de uma rede deve ser feita com escolhas cuidadosas, pois uma rede com muitas camadas escondidas ou muitos neurônios nessas camadas pode fornecer excelentes resultados para os dados de treinamento, mas, para os dados de validação, os resultados podem ser totalmente imprecisos ocasionando um problema denominado overfitting, que é quando a rede memoriza um padrão e não se torna capaz de realizar generalizações, é verificado no presente estudo que não há indícios da ocorrência deste problema uma vez que a variação entre o valor do erro para etapa de treinamento e para etapa de simulação são baixas e intrínsecas ao problema.

Vários estudos envolvendo redes neurais vêm sendo realizados com aplicações na área de alimentos, ligados a classificação de acordo com determinadas características. Sauthiera et al. (2019) fez uso de redes neurais em seu estudo de triagem dos compostos funcionais de Mangifera indica L. usando ACP e redes neurais onde determinou 12 substâncias polifenólicas por HPLC-DAD em amostras de manga e aplicou estes resultados em avaliações com RNA.

\section{Conclusões}

O desenvolvimento classificado para casca da manga a partir de redes neurais se mostrou eficiente apresentando um erro de $8,2 \%$ para etapa de simulação e com capacidade de classificar adequadamente 89 amostras das 97 amostras empregadas na etapa de simulação, porém a determinação da arquitetura ideal para rede neural é de difícil obtenção sendo necessário emprego de técnicas de otimização da rede como a utilização de algoritmos genéticos na etapa de treinamento para determinação da arquitetura mais adequada ao problema estudado e com isso reduzir o erro na etapa de simulação.

\section{Referências}

AJILA, C. M; U. J. S. P. RAO. Mango peel dietary fibre: Composition and associated bound phenolics. Journal of functional foods. v.5, n.1, p.444-450. JAN. 2013.

ALBERTON, A. C. M. Caracterização da Manga Tommy Atkins in natura e após a liofilização. Trabalho de Conclusão de Curso. Universidade Tecnológica Federal do Paraná UTFPR, campus Medianeira, p.10-21. MEDIANEIRA, 2014.

BHARGAVA, A.; A. BANSAL. Fruts and vegetables quality evaluation using computer vision: a review. Journal Of King Saud University- Computer And Information Sciences. 2018. 
BRASIL. Agência Nacional de Vigilância Sanitária. Resolução RDC n. 263, de 22 de set. de 2005. Regulamento técnico para produtos de cereais, amidos, farinhas e farelos. SET. 2005.

DEBSKA, B; B GUZOWSKA-SWIDER. Application of artificial neural network in food classification. Analytica Chimica Acta. 705, p.283-291. 2011.

DETMANN, E; M. A.de SOUZA; S.de C.VALADARES FILHO; A. C. de QUEIROZ; T. T. BERCHIELLI; E. de O. S. SALIBA; L. da S. CABRAL; D. dos S. PINA; M. M. LADEIRA; J.A.G. AZEVEDO. Métodos para análise de alimentos. Instituto nacional de ciência e tecnologia de ciência animal. $1^{\circ}$ ed. 2012.

IMRAN, M.; M. S. BUTT; F. M. ANJUM; J.I. SULTAN. Chemical profiling of diferente mango peel varieties. Journal of Nutrition. v.12, n.10, p.934-942. 2013.

INSTITUTO ADOLFO LUTZ. Normas analíticas do Instituto Adolfo Lutz. Métodos físico-químicos para análise de alimentos. São Paulo: IMESP, 2008.

LEMOS, D. M.; S. F. da SILVA; F. B. da SILVA; R. M. F. de FIGUEIRÊDO; E. P. de SOUSA. Isotermas de adsorção de água da farinha de cascas de manga. Anais do evento. Congresso Técnico Científico da Engenharia e da Agronomia. Fortaleza-CE, SET., 2015.

LEMOS, D. M.; S. F.DA SILVA; J. C. B. DE LIMA; F. B. DA SILVA; E. P. DE SOUSA. Parâmetros químicos, físicos e físico-químicos de resíduos da manga. Revista Verde de Agroecologia e Desenvolvimento Sustentável, v.8, n.2, p.01 - 03. Mossoró - RN, JUN., 2013.

MALDONADE, I. R.; P. G. B. CARVALHO; N.A. FERREIRA. Protocolo para determinação de açúcares totais em hortaliças pelo método de DNS. EMBRAPA. $1^{\circ}$ ED, MAR., 2013.

MENDES, B. de A. B. Obtenção, Caracterização e aplicação de farinha das cascas de abacaxi e de manga. Tese de Mestrado (74). Universidade Estadual do Sudoeste da Bahia (UESB), p. 45-47. Itapetinga -Bahia, 2013.

MIGUEL, A. C. A. Uso de película comestível, cloreto de cálcio e ácido ascórbico para a conservação do melão 'amarelo' minimamente processado. Tese de mestrado (196). Universidade de São Paulo escola superior de agricultura "Luiz Queiroz", p. 17-33. Piracicaba, 2008.

MORENO, J. de S. Obtenção, caracterização e aplicação de farinha de resíduos de frutas em cookies. Tese de mestrado (82). Universidade estadual do sudoeste da Bahia, p. 15-22. Itapetinga-BA, 2016.

OLIVAS, G. I.; D. S. MATTINSON; G. V. BARBOSA-CÁNOVAS. Alginate coatings for preservation of minimally processed 'Gala' apples. Postharvest Biology and Technology, 45 p.89-96. 2007.

PADILHA, T.; C. BASSO. Biscoitos com resíduo de manga, maracujá e jabuticaba. Disciplinarum Scientia. Série: Ciências da Saúde, v.16, n.1, p.79-88. Santa Maria, MAI., 2015. 
PULIGUNDLA, P; V. S. R. OBULAM; S. E. OH; C. MO. Biotechnological Potentialities and Valorization of Mango Peel Waste: A Review. Sains Malaysiana. v.43, n.12, p.1901-1906. 2014.

RAMOS, J. P. S. Redes Neurais Artificias na classificação de frutos: cenário bidimensional. Ciência Agrotecnologia. v.27, n.2, p.356-362. Lavras, 2003.

REINOSO, A. C. L. Utilização de resíduos de mangas Tommy atkins para elaboração de barras de cereais. Tese de doutorado (99). Universidade federal de Sergipe, p. 4-66. São Cristóvão, 2017.

REINOSO, A. C. L.; R. R. DE SOUZA; M. A. G. CARNELOSSI; A. M. DA CONCEIÇÃO C. C. DE S. BERY; J. K.DE OLIVEIRA. Efeitos das temperaturas na conservação dos minerais em farinhas de cascas de mangas. Interfaces Científicas - Saúde e Ambiente, v.5, n.2, p. 25 - 32. Aracaju, FEV., 2017.

RYBKA, A. C. P., A. de S. LIMA, R. de C. M. R. NASSUR. Caracterização da farinha da casca de diferentes cultivares de manga. Anais do evento. ENCICLOPEDIA BIOSFERA. Centro Científico Conhecer, v.15 n.27; p. 12, Goiânia, 2018.

SAUTHIER, M. C. da S.; E. G. P. da SILVA; B. R. da S. SANTOS; E. F. R. SILVA; J.da C. CALDAS; L. A. C. MINHO; A. M. P. dos SANTOS; W. N. L. dos SANTOS. Screening of mangifera indica L. functional contente using PCA and neural network (ANN). Foods chemistry. 273, p. 115-123. 2019.

SILVA, D. A. DA; S. M. M. CALISTO. Avaliação físico-química e sensorial da Manga Tommy Atkins submetida à desidratação. Trabalho de conclusão de curso (39). Universidade Tecnológica Federal do Paraná, p. 5-9. Londrina, 2013.

SOARES F. C.; A. D. ROBAIANA; M. X. PEITER; J. L. RUSSI; G. A. VIVAN. Redes neurais artificiais na estimativa da retenção de água do solo. Ciência Rural, v.44, n.2, p.293300, Santa Maria, FEV, 2014. 